\title{
Optimalisasi Produksi dan Maksimalisasi Keuntungan Usaha Ternak Sapi Potong dengan Sistem Integrasi Sapi-Sawit di Kabupaten Dharmasraya
}

\section{Product Optimalization and Profit Maximization of Integrated Beef Cattle and Palm Oil Farming System in Dharmasraya District}

\author{
I. Indrayani, J. Hellyward \\ Fakultas Peternakan Universitas Andalas, Kampus Unand Limau Manis Padang \\ e-mail : ida.indrayani@gmail.com \\ (Diterima: 03 2015; Disetujui: 13 2015)
}

\begin{abstract}
ABSTRAK
Penelitian ini dilakukan di Kabupaten Dharmasraya. Penelitian ini bertujuan untuk mengetahui tingkat produksi dan keuntunganmaksimal peternak sapi potong yang berintegrasi dengan sawit di Kecamatan Koto Besar Kabupaten Dharmasraya. Pemilihan lokasi dilakukan secara purposive, dengan pertimbangan bahwa Kecamatan Koto Besar merupakan Kecamatan dengan populasi sapi potong terbanyak kedua di Dharmasraya dan melakukan integrasi sapi dengan sawit. Data dikumpulkan melalui wawancara dengan 30 responden dengan bantuan kuesioner dan recording sebagai instrumen penelitian. Data dianalisis dengan persamaan regresi kuadratik dan regresi linear. Hasil analisis menunjukkan persamaan Biaya Produksi TC $=24,1-7,1 \mathrm{Q}+0,3 \mathrm{Q}^{2}$ dan $\mathrm{TR}=7.191 .820 \mathrm{Q}-1.537 .094 \mathrm{Q}^{2}$. Produktivitas sapi di wilayah penelitian selama 3 tahun pemeliharaan setiap satu ekor induk sapi melahirkan rata-rata 1,7 ekor anak sapi. Keuntungan yang diperoleh peternak Rp.4.154.792,-/ekor induk/3 tahun. Sementara produksi optimal usaha ternak sapi bibit selama masa pemeliharaan 3 tahun untuk satu ekor induk sapi adalah 2,33 ekor anak.Dengan demikian keuntungan maksimal peternak seharusnya bisa mencapai Rp.8.412.202,untuk setiap 1 ekor induk yang dipelihara selama 3 tahun pemeliharaan.
\end{abstract}

Kata Kunci : Produksi, keuntungan, optimal, integrasi, sapi potong

\section{ABSTRACT}

The research analyzed the production level and profit maximization of integrated beef cattle and palm oil plantation system in Koto Besar sub-district, Dharmasraya. Koto Besar sub-district was selected as study location based on two reasons; the 2nd highest in beef cattle population and the existance of integrated beef cattle and palm oil plantation. Primary data were collected using an interview to 30 respondents on the quesioner basis as well as data recording as the study instrument. Both regression quadratic as a function of cost and linear regression as a function of revenue used as tools of analysis. The result showed that equation of cost TC $=24.1-7.1 Q+$ $0.3 Q 2$ and equation of revenue $T R=7.191 .820 Q-1.537 .094 Q 2$. For 3 years, a cow productivity had calf rate at 1.7 head and profit gain at Rp.4.154.792,-. Although the optimal calf production should be 2.33 head at each cow, and profit maximal of the farmers Rp.8.412.202,-.

Keywords : production, profit, optimal integration, beef cattle

\section{PENDAHULUAN}

Usaha ternak Ruminansia khususnya ternak sapi menghadapi tantangan penyusutan lahan, dimana lahan adalah unsur utama bionomik ternak. Sejalan dengan susutnya lahan, berkurang pula peluang produksi hijauan dan persediaan hasil samping pertanian 
yang dapat dijadikan pakan ternak sapi. Sementara itu usaha ternak sapi dituntut untuk memacu produksi untuk memenuhi permintaan pasar dalam negeri yang terus berkembang. Namun, memacu produksi ternak sapi melalui pemberian konsentrat tidaklah ekonomis; karena harganya terlalu mahal dan cenderung terus membumbung.Untuk menghadapi tantangan tersebut, pengembangan usaha ternak sapi ke depan dapat bertumpu pada pemanfaatan hasil samping perkebunan, yang tidak lagi dianggap sebagai limbah, namun sebagai sumber daya (Suharto, 2003).

Keuntungan sistem integrasi tanaman ternak menurut Handaka et al (2009) adalah: (1) diversifikasi penggunaan sumberdaya, (2) mengurangi resiko usaha, (3) efisiensi penggunaan tenaga kerja, (4) efisiensi penggunaan input produksi, (5) mengurangi ketergantungan energi kimia, (6) ramah lingkungan, (7) meningkatkan produksi, dan (8) pendapatan rumah tangga petani yang berkelanjutan. Sistem integrasi tanaman - ternak memadukan sistem usahatani tanaman dengan sistem usahatani ternak secara sinergis sehingga terbentuk suatu sistem yang efektif, efisien dan ramah lingkungan. Pemeliharaan ternak sapi di areal kebun kelapa sawit merupakan salah satu bentuk untuk memaksimalkan pemanfaatan lahan yang ada.

Kabupaten Dharmasraya merupakan salah satu wilayah pemekaran yang saat ini mengalami perkembangan yang cukup pesat di berbagai sektor pembangunan. Perekonomian Kabupaten ini termasuk cukup pesat pertumbuhannya, dimana sektor pertanian secara umum menjadi andalan bagi perekonomian masyarakat. Penggunaan lahan terbesar di Kabupaten Dharmasraya sebagian besar adalah lahan perkebunan yang menjadikan Kabupaten ini sebagai salah satu sentral perkebunan di Sumatera Barat yang terutama dimotori oleh perkebunan kelapa sawit dan perkebunan karet. Subsektor tanaman perkebunan sendiri pada tahun 2012 ini memberikan kontribusinya sebesar 20,03 persen. Sumbangan subsektor peternakan mengalami sedikit kenaikan dari tahun sebelumnya, dimana pada tahun 2011 kontribusi subsektor ini tercatat sebesar 3,24 persen sedangkantahun 2012 mampu menyumbang sebesar 3,34 persen.Saat ini peternakan sapi dan kebun sawit menjadi prioritas utama untuk dikembangkan di Kabupaten Dharmasraya, karena didukung juga dengan populasi ternak sapi merupakan populasi terbanyak dibandingkan ternak besar lainnya yaitu 31.449 ekor (Badan Pusat Statistik Kabupaten Dharmasraya, 2014).

Kecamatan Koto Besar merupakan Kecamatan dengan populasi sapi potong terbanyak kedua di Kabupaten Dharmasraya, dimana pada tahun 2014 berjumlah 4.737 ekor dengan luas kebun sawit perkebunan rakyat sebesar 31.784,78 Ha (Badan Pusat Staistik Kabupaten Dharmasraya, 2014). Dengan semakin pesatnya perkembangan ternak berbasis integrasi sapi-sawit di Dharmasraya, sejalan dengan itu penduduk di Kecamatan Koto Besar juga sudah menjadikan integrasi sapi-sawit sebagai salah satu alternative usaha andalan. Sehubungan dengan itu di Wilayah Koto Besar (Sitiung IV) sudah dibentuk Kebun Percobaan yang mengaplikasikan integrasi antara sapi dengan sawit. Pada tahun 2013 BPTP Sumatera Barat telah melakukan suatu kegiatan pengkajian di kebun percobaan tersebut dengan judul "Kajian Pengembangan Teknologi Pakan Sapi Berbasis Sawit Mendukung Integrasi Sapi-Sawit di KP Koto Besar, Sumatera Barat"yang bertujuan untuk memperoleh teknologi pakan sapi potong berbasis hasil ikutan tanaman sawit dan pemanfaatan pupuk organik bagi tanaman sawit di Kebun Percobaan Situng IV menunjang pengembangan integrasi sapi-sawit di wilayah Sumatera Barat.

Dari berbagai potensi yang ada, yang masih merupakan masalah adalah peternak sapi belum punya pengetahuan yang memadai akan untung ruginya usaha ternak sapi. Dengan belum lengkapnyainformasi tersebut sehingga peternak maupun pengusahasapi tidak berani mengembangkan usaha tersebut mengingat usaha ini membutuhkan investasi yang cukup besar. Sementara itu prospek pengembangan sapi potong dalam rangka peningkatan produksi daging untuk memenuhi 
permintaan lokal, dalam maupun luar negeri sangat memberikan gambaran yang cukup cerah. Seperti diketahui biaya operasional terbesar dalam usaha peternakan adalah biaya pakan sekitar 60-70\%, dengan jalan mengintegrasikan kegiatan pemeliharaan ternak dengan kegiatan usaha tani lainnya akan dihasilkan efisiensi biaya produksi yang tinggi. Menurut Chaniago (2009), tujuan integrasi kelapa sawit dengan ternak sapi adalah untuk mendapatkan produk tambahan yang bernilai ekonomis, peningkatan efisiensi usaha, peningkatan kualitas penggunaan lahan, peningkatan kelenturan usaha menghadapi persaingan global, dan menghasilkan lingkungan yang bersih dan nyaman.

Masalah yang sering dihadapi oleh petani-peternak dalam melaksanakan usaha tani adalah kurangnya pengetahuan cara berproduksi. Pada umumnya petani hanya menginginkan jumlah produksi yang tinggi, tetapi kurang memperhatikan cara berproduksi. Kurangnya pengetahuan tentang jumlah sarana produksi yang tepat menyebabkan peningkatan biaya produksi yang ada dan pada akhirnya mempengaruhi keuntungan usahatani. Keuntungan maksimal hanya dapat diperoleh jika produsen memilih tingkat produksi tertentu atau berproduksi pada tingkat optimal.

Adapun penelitian ini bertujuan untuk :

1. Menganalisa produksi dan keuntungan peternak sapi potong yang berintegrasi dengan sawit di Kecamatan Koto Besar Kabupaten Dharmasraya

2. Menganalisa produksi optimal dan keuntungan maksimal peternak sapi potong yang berintegrasi dengan sawit di Kecamatan Koto Besar Kabupaten Dharmasraya

\section{METODE}

Penelitian ini dilakukan di Kecamatan Koto Besar Kabupaten Dharmasraya. Pemilihan lokasi dilakukan secara purposive, dengan pertimbangan bahwa Kecamatan Koto Besar merupakan Kecamatan dengan populasi sapi potong terbanyak kedua dan melakukan integrasi sapi dengan sawit. Adapun populasi dalam penelitian ini adalah seluruh peternak sapi potong di wilayah Koto Besar (Kenagarian Koto Tonggi dan Koto Gadang) yang sudah mengintegrasikan pemeliharaan sapi dengan kebun kelapa sawit. Jumlah sampel ditetapkan secara quota yaitu 30 peternak. Pengambilan sampel dilakukan secara snowball sampling.

Variabel yang diukur dalam penelitian ini adalah biaya yang dikeluarkan, penerimaan, keuntungan, produksi optimal dan keuntungan maksimum usaha sapi potong yang terintegrasi dengan kebun sawit. Data yang dibutuhkan dalam penelitianini berupa data primer dan data sekunder. Data-data primer tersebut berupa biaya produksi meliputi biaya pakan, biaya tenaga kerja, biaya obat, biaya penyusutan kandang dan alat, jumlah produksi, harga jual ternak dan pertambahan nilai ternak. Sedangkan datasekunder diperoleh melalui studi kepustakaan dan dari berbagai insrtansi.

Data yang diperoleh akan disajikan dalam bentuk tabel, kemudian dianalisis, dibahas dan ditarik kesimpulan. Jumlah biaya yang dikeluarkan dalam suatu usaha diketahui dengan menggunakan pendekatan persamaan yang dikemukakan oleh Boediono (1989) sebagai berikut :

$$
\begin{array}{ll}
\mathrm{C} & =\mathrm{f}(\mathrm{Q}) \\
\mathrm{C} & =\mathrm{a}+\mathrm{bQ}+\mathrm{cQ} 2
\end{array}
$$

Keterangan:

$\mathrm{C}=$ Cost (biaya);

a = Koefisien biaya tetap;

$\mathrm{b}, \mathrm{c}=$ Koefisien biaya tidak tetap;

$\mathrm{Q}=$ Quantity (jumlah hasil produksi).

Penyelesaian persamaan biaya dapat menggunakan persamaan kuadratik :

$$
\begin{aligned}
& \mathrm{C}=\mathrm{a}+\mathrm{bQ}+\mathrm{cQ} 2 \\
& \text { Maka : } \\
& \Sigma \mathrm{C}=\mathrm{na}+\mathrm{bQ}+\mathrm{c} \Sigma \mathrm{Q} 2 \\
& \Sigma \mathrm{CQ}=\mathrm{a} \Sigma \mathrm{Q}+\mathrm{b} \Sigma \mathrm{Q} 2+\mathrm{c} \Sigma \mathrm{Q} 3 \\
& \Sigma \mathrm{CQ} 2=\mathrm{a} \Sigma \mathrm{Q} 2+\mathrm{b} \Sigma \mathrm{Q} 3+\mathrm{c} \Sigma \mathrm{Q} 4
\end{aligned}
$$

Nilai a, b, c dapat diperoleh dengan menggunakan penyelesaian persamaan determinan (Sudjana, 1998). Besarnya penerimaan/revenue menurutn Wasis (2000), ditentukan dengan pendekatan persamaan :

$$
\begin{array}{ll}
\mathrm{P} & =\mathrm{f}(\mathrm{Q}) \\
\mathrm{P} & =\mathrm{a}+\mathrm{bQ} \\
\mathrm{TR} & =\mathrm{P} . \mathrm{Q}
\end{array}
$$


maka :

$$
\begin{aligned}
& \mathrm{TR}=(\mathrm{a}+\mathrm{bQ}) \cdot \mathrm{Q} \\
& \mathrm{TR}=\mathrm{aQ}+\mathrm{bQ} 2
\end{aligned}
$$

dimana :

$\mathrm{TR}=$ penerimaan /revenue

$\mathrm{P}=$ harga $/$ price

$\mathrm{Q} \quad=$ jumlah produksi /Quantity

$\mathrm{a}, \mathrm{b}=$ konstanta, koefisien arah

maka :

$\Sigma \mathrm{P}=\mathrm{na}+\mathrm{b} \Sigma \mathrm{Q}$

$\Sigma P Q=a \Sigma Q+b \Sigma Q 2$

Untuk nilai a dan $b$ menurut Sudjana (1998), dapat dicirikan dengan menggunakan rumus sebagai berikut :

$$
\begin{aligned}
\mathrm{a}= & \frac{\sum P \sum Q^{2}-\sum Q \sum P Q}{n \sum Q^{2}-\left(\sum Q\right)^{2}} \\
\mathrm{~b}= & \frac{\sum P Q-\Sigma P \sum Q}{n \sum Q^{2}-\left(\sum Q\right)^{2}}
\end{aligned}
$$

Menurut Gaspersz (2001), tingkat produksi optimal dapat dicapai pada saat :

$$
\begin{array}{ll}
\mathrm{MR} & =\mathrm{MC} \\
\mathrm{dC} / \mathrm{dQ} & =\mathrm{dR} / \mathrm{dQ}=0
\end{array}
$$$$
\text { keterangan: }
$$

$\mathrm{MC}=$ Marginal cost (biaya tambahan);

MR = Marginal revenue (penerimaan tambahan);

$\mathrm{dC} / \mathrm{dQ}=$ Turunan pertama persamaan biaya;

$\mathrm{dR} / \mathrm{dQ}=$ Turunan pertama persamaan penerimaan.

Oleh Lincolin Arsyad (2000), besarnya keuntungan (laba) diperoleh dari :

$$
\begin{aligned}
& \pi \quad=\text { TR }-\mathrm{TC} \\
& \text { keterangan: } \\
& \pi \quad=\text { Profit (laba/keuntungan); } \\
& \mathrm{TR}=\text { Total revenue (penerimaan total); } \\
& \mathrm{TC}=\text { Total cost (biaya total). }
\end{aligned}
$$

Laba maksimum tercapai apabila turunan pertama laba/keuntungan sama dengan nol yaitu $\pi^{\prime}=0$, atau pada saat tambahan penerimaan (marginal revenue) sama dengan tambahan biaya (marginal cost).

\section{HASIL DAN PEMBAHASAN}

\section{Keragaan usaha Ternak Sapi Potong}

Sistem pemeliharaan yang dijalankan oleh peternak dengan pola integrasi sapi-sawit adalah sistem semi intensif dimana pada siang hari sapi ternak dilepas atau digembalakan di lahan kebun sawit dan pada sore hari ternak akan digiring berpidah tempat untuk ternak beristirahat, ada yang dikandangkan dan ada pula yang ditempatkan di area yang sekelilingnya dipagar. Menurut Yulianto dan Saparinto (2010) pemeliharaan semi intensif merupakan perpaduan pengembangan ekstensif dan intensif, dimana pada pola ini sapi-sapi pada siang hari ditambatkan atau digembalakan di ladang, kebun, atau pekarangan yang rumputnya tumbuh subur, dan sore harinya sapi dimasukkan kedalam kandang sederhana.

Keragaan usaha ternak sapi potong system integrasi sapi-sawit di Kecamatan Koto Besar Kabupaten Dharmasraya dapat dilihat pada Tabel 1.

Sebagian besar atau 93\% ternak sapi adalah milik sendiri dan hanya $7 \%$ dengan sistem seduaan. Ternak sapi dipelihara di kebun sawit milik sendiri, dimana peternak memiliki lahan sawit berkisar antara $2-4 \mathrm{Ha}$. Jenis sapi yang dipelihara di lokasi penelitian adalah sapi Bali dengan skala pemeliharaan beragam berkisar antara 2 - 30 ekor sapi, dimana jika diambil angka rata-rata menjadi 7

Tabel 1. Keragaan Usaha Sapi Potong Sistem Integrasi Sapi-Sawit di Kecamatan Koto Besar Kabupaten Dharmasraya

\begin{tabular}{llc}
\hline No & \multicolumn{1}{c}{ Uraian } & Rata-Rata \\
\hline 1 & Luas Lahan Sawit yang dimiliki & $2,475 \mathrm{Ha}$ \\
2 & Jenis Sapi & Sapi Bali \\
2 & Jumlah Sapi yang dipelihara & 7 ekor atau 4,5 ST \\
3 & Jumlah induk sapi & 3 ekor \\
4 & Umur awal induk sapi & $2-3$ Tahun \\
5 & Jumlah anak yang lahir (3 tahun terkhir) & 4,67 ekor \\
\hline
\end{tabular}


ekor per peternak dengan jumlah induk sapi 115 ekor atau rata-rata 3 ekor per peternak dan jumlah anak yang lahir $2-21$ ekor atau ratarata 4,7 ekor per peternak selama 3 tahun terakhir.

\section{Kapasitas Tampung}

Keberadaan padang penggembalaan sangat diperlukan, oleh karena itu, perlu adanya upaya pemanfaatan terhadap lahan kebun sawit yang dimiliki peternak dengan menentukan kapasitas tampung, sehingga lahan sawit yang sekaligus juga memproduksi hijauan makanan ternak dapat dimanfaatkan dengan optimal. Rata-rata produksi hijauan di bawah kelapa sawit umur 5-10 tahun adalah 10,479 ton/ ha/tahun dan pohon kelapa sawit umur 10-20 tahun adalah 14,827 ton/ha/tahun.

Didasarkan pada asumsi tersebut maka produksi hijauan rata-rata peternak di lokasi penelitian adalah 25.9 ton/tahun. Jika diasumsikan konsumsi hijauan sapi dewasa $30 \mathrm{~kg} / \mathrm{hari}$ maka kapasitas tampung kebun sawit yang dimiliki peternak adalah 2.4 ekor sapi dewasa (2.4ST).Sementara jumlah ternak sapi yang dimiliki peternak adalah rata-rata 7 ekor atau 4.5 ST. Dengan demikian dapat dikatakan bahwa untuk memenuhi kebutuhan pakan ternak dengan pemeliharaan integrasi sapisawit, maka peternak harus juga memanfaatkan limbah kebun sawit selain hijaun agar kebutuhan pakan ternak sapi dapat terpenuhi. Limbah kebun sawit lain yang dapat dimanfaatkan peternak adalah berupa pelepah dan daun sawit. Daya dukung 1 ha kebun sawit rakyat (dengan memanfaatkan hijauan, daun, dan pelepah sawit) adalah untuk 1,6 ekor sapi dewasa. Sementara jika semua biomasa limbah pengolahan kelapa sawit dimanfaatkan, maka untuk setiap hektar kebun sawit mampu menyediakan pakan untuk 2,6 ekor sapi dewasa.

\section{Biaya Produksi Usaha Ternak Sapi Potong}

Biaya produksi adalah seluruh biaya yang dikeluarkan petani dalam menjalankan usahanya. Adapun biaya-biaya yang dihitung pada usaha ternak sapi potong terdiri dari biaya hijauan, tenaga kerja, obat-obatan, penyusutan kandang dan peralatan. Biaya pakan berupa hijauan dihitung berdasarkan jumlah jam kerja yang dihabiskan peternak setiap harinya untuk mencari hijauan untuk pakan ternak pada malam hari. Biaya tenaga kerja dihitung berdasarkan jam kerja yang dihabiskan peternak untuk memantau dan menggiring ternak mereka pada sore hari dikali dengan tingkat upah yang berlaku. Tingkat upah yang berlaku di lokasi penelitian Rp.50.000/HOK. Rata-rata jam kerja yang dihabiskan peternak rata-rata 1,2 jam per hari.

\section{Biaya tetap}

Biaya tetap merupakan biaya yang jumlahnya tetap tidak tergantung pada volume produksi atau biaya yang dikeluarkan untuk input tetap yang dapat digunakan untuk beberapa kali periode produksi. Biaya tetap pada usaha ternak sapi potong terdiri dari biaya penyusutan kandang dan peralatan.

a. Biaya penyusutan kandang

Kandang merupakan tempat yang berfungsi sebagai tempat istirahat dan melindungi ternak dari hujan dan panas pada siang hari. Biaya penyusutan kandang dihitung dengan menggunakan metode garis lurus yaitu dengan cara membagi harga barang dengan umur ekonomis. Biaya penyusutan kandang yang diperhitungkan rata-rata Rp.2.480.000 selama 3 tahun analisis, dimana biaya pembuatan kandang berkisar antara Rp.750.000 Rp.1.500.000/ekor dan umur ekonomis kandang adalah 5 tahun.

b. Biaya Penyusutan Peralatan

Peralatan yang dimaksud dalam usaha sapi potong ini adalah berupa cangkul dan sekop. Biaya penyusutan untuk kedua alat itu adalah rata-rata $\mathrm{Rp} .83 .833$ selama 3 tahun anaisis dengan umur ekonomis peralatan adalah 3 tahun.

\section{Biaya Variabel}

Biaya variabel merupakan biaya produksi yang jumlahnya berubah tergantung pada volume produksi, atau biaya yang dikeluarkan untuk seluruh input yang bersifat variabel yaitu input yang habis dalam satu kali proses produksi.

\section{a. Biaya Pakan}

Pakan yang diberikan peternak adalah 
Tabel 2. Biaya Produksi Usaha Ternak Sapi Potong Sisitem Integrasi Sapi-Sawit di Kecamatan Koto besar, Dharmasraya

\begin{tabular}{llrr}
\hline No & \multicolumn{1}{c}{ Biaya Produksi } & \multicolumn{1}{c}{$\begin{array}{c}\text { Jumlah } \\
(\mathrm{Rp})\end{array}$} & Persentase (\%) \\
\hline $\mathbf{1}$ & Biaya variable & 9.006 .375 & \\
& a. Biaya Pakan & 95.833 & 2,7 \\
b. Biaya Obat-obatan & 8.212 .500 & 1,4 \\
c. Biaya Tenaga Kerja & $\mathbf{1 7 . 3 1 4 . 7 0 8}$ & $\mathbf{9 5 , 1}$ \\
Total & & 1,5 \\
$\mathbf{2}$ & Biaya tetap & 2.480 .000 & 0,2 \\
& a. Biaya Penyusutan Kandang & 83.833 & \\
b. Biaya Penyusutan Peralatan & $\mathbf{2 . 5 6 3 . 8 3 3}$ & $\mathbf{1 0 0 , 0}$ \\
\hline & Total & $\mathbf{1 9 . 8 7 8 . 5 4 1}$ & \\
\hline
\end{tabular}

Sumber : Hasil Penelitian, 2015

berupa hijauan yang tumbuh di area lahan kebun sawit. Pada siang hari ternak sapi dilepaskan di area lahan kebun sawit, artinya ternak mencari sendiri hijauan sebagai pakannya. Sementara kebutuhan hijauan ternak untuk malam hari disediakan oleh peternak. Lama waktu yang dibutuhkan peternak untuk mencari hijauan berkisar antara $0.5-3$ jam/hari. Berdasarkan kondisi tersebut biaya hijauan yang diperhitungkan rata-rata $\mathrm{Rp}$. 9.006.375 selama 3 tahun analisis.

b. Biaya Obat-obatan

Biaya obat-obatan hanya dikeluarkan jika ada gejala ternak yang sakit, dimana biasanya sapi akan disuntik oleh dokter hewan atau petugas kesehatan hewan di daerah setempat. Biaya obat-obatan yang dikeluarkan rata-rata Rp. 95.833 selama 3 tahun analisis.

c. Biaya Tenaga Kerja

Kondisi empiris di daerah penelitian, bahwa proporsi tenaga kerja yang banyak digunakan untuk pengelolaan sapi potong adalah tenaga kerja keluarga. Curahan jam kerja peternak untuk pengelolaan sapi potong adalah 1,2 jam hari yang digunakan untuk untuk memantau dan menggiring ternak mereka pada sore hari serta membersihkan kandang. Biaya tenaga kerja rata-rata yang dikeluarkan Rp. 8.212500 .
Rincian biaya tetap dan variabel pada usaha ternak sapi potong di Kecamatan Koto Besar Kabupaten Dharmasraya dapat dilihat pada Tabel 2.

\section{Penerimaan dan Pendapatan Usaha Ternak Sapi Potong}

Penerimaan usaha ternak sapi potong terdiri dari penerimaan tunai dan non tunai. Penerimaan tunai berasal dari hasil penjualan sapi potong dalam 3 tahun pemeliharaan, dan penerimaan non tunai dihitung berdasarkan nilai anak sapi yang belum terjual. Penerimaan tunai peternak sebesar Rp.8.166.667 dan non tunai sebesar Rp.15.866.667 sehingga penerimaan keseluruhan berjumlah Rp. 24.033.333. Berdasarkan penerimaan dan rincian biaya diatas maka keuntungan peternak sapi potong selama 3 tahun adalah sebesar Rp. 4.154.792.

\section{Persamaan Total Biaya (Total Cost) dan Persamaan Penerimaan (Total Revenue)}

Berdasarkan hasil data penelitian 30 responden pada ternak sapi potong diperoleh persamaan biaya (TC) dengan menggunakan regresi kuadratik, dimana :

$$
\mathrm{TC}=\mathrm{a}+\mathrm{bQ}+\mathrm{cQ} \mathrm{Q}^{2}
$$

Nilai $a, b, c$ dapat diperoleh dengan menggunakan penyelesaian persamaan determinan (Sudjana, 1998).

$$
\left(\begin{array}{ccc}
n & \Sigma Q & \Sigma Q^{2} \\
\Sigma Q & \Sigma Q^{2} & \Sigma Q^{3} \\
\Sigma Q^{2} & \Sigma Q^{3} & \Sigma Q^{4}
\end{array}\right)\left(\begin{array}{l}
a \\
b \\
c
\end{array}\right)=\left(\begin{array}{c}
\Sigma Q \\
\Sigma Q \\
\Sigma Q^{2}
\end{array}\right)
$$




$\left(\begin{array}{ccc}30 & 140 & 1304 \\ 140 & 1304 & 19160 \\ 1304 & 19160 & 337088\end{array}\right)\left(\begin{array}{l}a \\ b \\ c\end{array}\right)=\left(\begin{array}{c}140 \\ 140 \\ 1304\end{array}\right)$

Sehingga didapatkan nilai $\mathrm{a}, \mathrm{b}$ dan $\mathrm{c}$ berturutturut adalah 24.1, -7.1 dan 0.3

Maka

$$
\mathrm{TC}=24.1-7.1 \mathrm{Q}+0.3 \mathrm{Q}^{2}
$$

Persamaan penerimaan (TR) diperoleh dengan menggunakan persamaan regresi linier melalui hubungan harga dengan produk, dimana :

$$
\mathrm{TR}=\mathrm{aQ}+\mathrm{bQ}^{2},
$$

Untuk nilai a dan b menurut Sudjana(1998), dapat dicirikan dengan menggunakan rumus sebagai berikut :

$$
\begin{gathered}
\mathrm{a}=\frac{\sum P \sum Q^{2}-\sum Q \sum P Q}{n \sum Q^{2}-\left(\sum Q\right)^{2}} \\
\mathrm{~b}=\frac{\sum P Q-\sum P \sum Q}{n \sum Q^{2}-\left(\sum Q\right)^{2}}
\end{gathered}
$$

dimana $\mathrm{P}$ adalah harga output dalam hal ini sapi yang dijual dengan harga berkisar antara Rp.7.000.000 sampai Rp.9.000.000, dan Q adalah produksi dalam hal ini jumlah anak yang lahir selama 3 tahun yaitu rata-rata masing-masing peternak 4.67 , sehingga $\Sigma \mathrm{Q}$ adalah 140

Maka

$$
\mathrm{TR}=7.191 .820 \mathrm{Q}-1.537 .094 \mathrm{Q}^{2}
$$

\section{Produksi Optimal dan Keuntungan Maksimal}

Perusahaan memperoleh laba maksimum, jika menghasilkan tingkat output pada saat penerimaan marjinal dari hasil tambahan penjualan satu unit outputnya sama dengan biaya marjinal untuk menghasilkan output tersebut (Nicholson, 2002). Produksi optimal diperoleh pada saat turunan pertama persamaan penerimaan sama dengan turunan pertama persamaan biaya $(\mathrm{MR}=\mathrm{MC})$.

Produktivitas sapi di wilayah penelitian selama 3 tahun pemeliharaan setiap satu ekor induk sapi melahirkan rata-rata 1,7 ekor anak sapi. Keuntungan yang diperoleh peternak Rp.4.154.792/ekor induk/3 tahun. Sementara produksi optimal usaha ternak sapi bibit selama masa pemeliharaan 3 tahun untuk satu ekor induk sapi adalah 2,33 ekor anak.
Dengan demikian keuntungan maksimal peternak seharusnya bisa mencapai Rp. 8.412.202 untuk setiap 1 ekor induk yang dipelihara selama 3 tahun pemeliharaan. Hal ini disebabkan rendahnya angka calving rate atau tingkat kelahiran anak sapi di wilayah penelitian.

Menurut Ahyari (2003) dalam Mursidah (2009), tingkat optimal pendapatan akan tercapai bila penggunaan faktor-faktor produksi telah efesien dan harga yang berlaku dapat menjamin keadaan tersebut, sehingga produksi yang diperoleh mencerminkan tingkat efesiensi dari usahataninya. Namun pada umumnya petani lebih bisa mengukur tingkat efesiensi produksi dari besarnya hasil dan tidak dari rendahnya biaya yang telah dikeluarkan untuk memproduksi hasil tersebut (Mubyarto, 2005)

\section{KESIMPULAN}

Berdasarkan hasil analisis dan pembahasan dapat ditarik kesimpulan sebagai berikut:

1. Total produksi yang dicapai peternak untuk setiap satu ekor induk yang dipelihara ratarata sebesar 1,7 ekor anak sapi/3tahun/ sehingga pendapatan yang diperoleh oleh peternak sapi di Kecamatan Koto Besar sebesar Rp. 4.154.792/ 3 tahun pemeliharaan.

2. Produksi optimal yang bisa dicapai oleh Peternak untuk setiap satu ekor induk yang dipelihara adalah sebesar 2,33 ekor anak sapi selama 3 tahun pemeliharaan, sehingga didapatkan pendapatan maksimal yang dicapai pada produksi optimal yaitu sebesar Rp. 8.412.202,-

\section{DAFTAR PUSTAKA}

Ahyari, A. 2003. Manajemen Produksi dan Pengendalian Produksi. LPUGM, Yogyakarta.

Badan Pusat Statistik, 2014. Dharmasraya dalam angka 2014. Badan Pusat Statistik Provinsi Sumatera Barat.

Boediono. 1989. Ekonomi mikro. BPFE, Yogyakarta. 
Chaniago, T. 2009. Perspektif pengembangan ternak sapi di kawasan perkebunan sawit. Prosiding Workshop Nasional Dinamika dan Keragaan Sistem Integrasi Ternak - Tanaman: Padi, Sawit, Kakao. (In Press). Pusat Penelitian dan Pengembangan Peternakan. Bogor.

Direktorat Jenderal Peternakan. 2009. Kebijakan pengembangan sapi potong di Indonesia. Prosiding Workshop Nasional Dinamika dan Keragaan Sistem Integrasi Ternak - Tanaman: Padi, Sawit, Kakao. (In Press). Pusat Penelitian dan Pengembangan Peternakan. Bogor.

Gaspersz, V. 2001. Ekonomi Manajerial Pembuatan Keputusan Bisnis. PT. Gramedia Pustaka Utama, Jakarta.

Handaka, A. Hendriadi, dan T. Alamsyah. 2009. Perspektif pengembangan mekanisasi pertanian dalam sistem integrasi ternak - tanaman berbasis sawit, padi, dan kakao. Prosiding Workshop Nasional Dinamika dan Keragaan Sistem Integrasi Ternak - Tanaman: Padi, Sawit, Kakao. (In Press). Pusat Penelitian dan Pengembangan Peternakan. Bogor.

Lincolin A. 2000. Ekonomi Manajerial. Edisi ke III. Cetakan 6. BPFE, Jakarta.
Mubyarto, 2005. Pengantar Ekonomi Pertanian. LP3ES, Jakarta.

Mursidah. 2009. Optimalisasi pendapatan usahatani kelapa sawit. Jurnal EPP. 6(2): 9-15.

Nicholson, W. 1999. Teori Ekonomi Mikro :Prinsip dan Pengembangannya. Terjemahan Deliarnov. PT. Raja Grafindo Persada. Jakarta.

Nicholson, W. 2002. Mikroekonomi Intermediate dan Aplikasi. Terjemahan. Edisi kedelapan. Penerbit Erlangga. Jakarta.

Santoso, U. 2008. Mengelola Peternakan Sapi Secara Profesional. Penebar Swadaya, Jakarta.

Sudjana. 1998. Teknik Analisis Regresi dan Korelasi Bagi para Peneliti. Tarsito. Bandung

Suharto. 2003. Pengalaman pengembangan usaha sistem integrasi sapi - kelapa sawit di Riau. Prosiding Lokakarya Nasional Kelapa Sawit - Sapi. Badan Litbang Pertanian. Bogor. Pp. 57-63.

Wasis. 2000. Pengantar Ekonomi Mikro. Alumni, Bandung.

Yulianto, P dan C. Saparinto. 2010. Pembesaran Sapi Potong Secara Intensif. Penebar Swadaya. Jakarta 